\title{
Application of Virtual Simulation Technology in Traditional Culture Communication
}

\author{
Lifang $\mathrm{GUO}^{1}$ \\ Dalian Polytechinic University, School of Foreign Languages, Dalian, 116034, China
}

\begin{abstract}
Computer virtual simulation technology is integrated into the new media system and organically combined with excellent traditional culture to provide an organic carrier and platform for the improvement of people's cultural literacy. This paper analyzes the means of traditional cultural communication, studies the foundation and strategy of integrating computer virtual simulation technology into the cultural communication system of new media, and formulates the steps and plans of computer virtual simulation technology to promote the improvement of people's cultural literacy.
\end{abstract}

Keywords. Virtual simulation, new media, traditional culture

\section{The background}

With the development of computer science and technology, the computer virtual simulation technology has become an important technical means in human science. In recent years, the comprehensive application of computer simulation technology in various fields makes it develop effectively. Modern society has also become an information-based society, and the era we are living in has also become the era of new media [1]. New media is the media form emerging under the new technical support system, such as digital magazine, digital newspaper, digital broadcast, mobile phone SMS, application software and so on. According to the "2020-2026 Market Prospect Planning and Market Prospect Trend Analysis Report of China's Mobile APP Industry" released by Zhiyan Consulting, among Internet users of all ages, mobile phone users aged 15-19 have the largest number of mobile apps per capita, reaching 84 . The second is the group of mobile Internet users aged 20-29, with 65 apps per capita. The average number of mobile phone users aged 60 and above was 37 (figure 1).

\footnotetext{
${ }^{1}$ Corresponding Author, Lifang GUO, Dalian Polytechinic University, School of Foreign Languages, Dalian, 116034, China; E-mail: guo_lifang@yeah.net.
} 


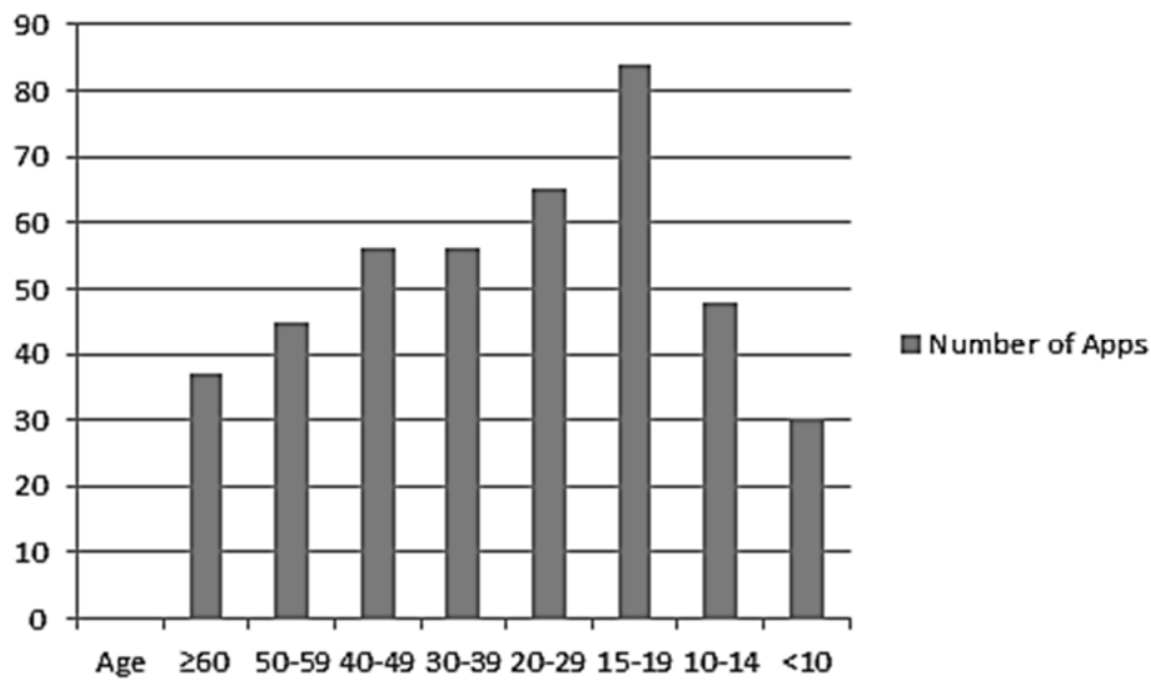

Figure 1. Number of apps per person in each age group.

Compared with the traditional media of newspapers, broadcasting, publishing and film and television, new media is vividly called "the fifth media". New media is a mass media platform with mobile phones as audio-visual terminals and mobile Internet as the platform for personalized instant information transmission. It takes the public as the communication target, the orientation as the communication purpose, the timely as the communication effect, and the interaction as the communication application. Many new technologies such as computer virtual simulation have also been widely used in media.

Faced with the impact and influence of foreign culture, the expansion of traditional culture is threatened. Therefore, we must strengthen the protection and inheritance of traditional culture. As a unique spiritual phenomenon, culture is the soul of a country and a nation. Cultural confidence refers to a nation, a country and a political party's full affirmation and active practice of their own cultural values and firm confidence in the vitality of their culture. In 2014, General Secretary Xi jinping called for greater confidence in culture and values. Since then, cultural confidence has become the "fourth confidence" of socialism with Chinese characteristics, after confidence in the path, theory and system. Adhering to the cultural confidence of socialism with Chinese characteristics can give the Chinese people more profound spiritual confidence, promote cultural security and national independence, and better promote national prosperity. As the power source of cultural confidence, China's excellent traditional culture is of great significance and must be inherited and developed. Using virtual simulation technology to spread excellent traditional culture will be conducive to the inheritance and development of culture and the practice of socialist core values. 


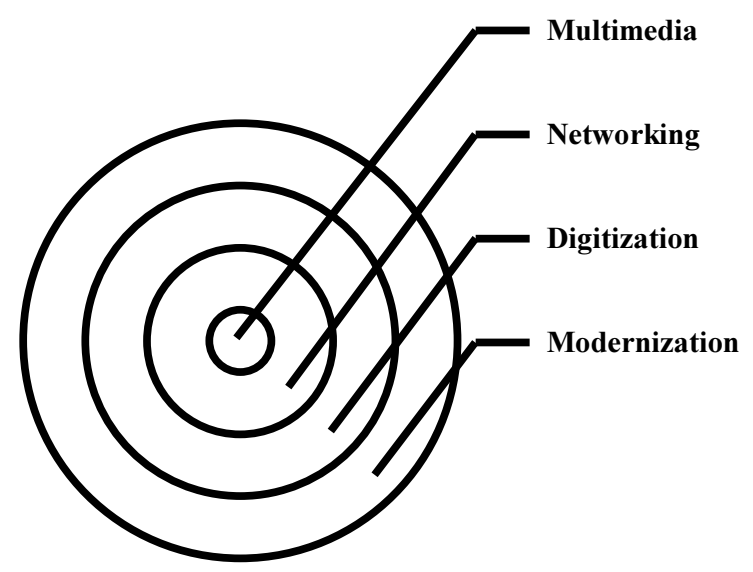

Figure 2. Diversification of computer tech to realize traditional culture

\section{The Mode of Traditional Culture Communication in the New Media Era}

New media is a kind of innovative media based on digital information technology and characterized by interactive communication. It is a media form that appears and influences on the basis of computer information processing technology. In the competition between new media and traditional media in the pattern of beach culture, people's attention has been seized to a great extent. How to make use of people's attention, spread the excellent Traditional Chinese culture, improve the social science and cultural literacy of the group, need to pay attention to the following aspects.

\subsection{Content Definition of Traditional Culture}

The communication of traditional culture relies on the means of new media, and the communication content of traditional media should be inherited and developed. Because new media do not appear spontaneously and in isolation, but gradually emerge from the morphological changes of the old media, and each new media takes an old media as its own content. All forms of communication media coexist and evolve together in an ever-expanding and complex adaptive system. Every time a new form appears and develops, it will affect the development of other existing media forms for a long time and to varying degrees. The new media will increase the main features of the original media forms and innovate from the aspect of communication content. We should dig suitable materials from the excellent traditional Chinese culture. Focus on the characteristics of different industries and regions, consider the cultural and historical perspectives involved, explore and explore the breadth, depth and temperature of different fields; Pay attention to the audience's humanistic quality, scientific spirit and so on. Thematic content should not only integrate history and traditional culture, but also pay attention to how traditional culture can better serve modern people, so as to face various problems existing in the real society.

Clarify the leading institutions for the dissemination of cultural knowledge by new media, and sort out cultural and educational resources. What institutions need to play a 
leading role in disseminating traditional culture and improving people's cultural literacy, and what departments and personnel need to participate in cooperation. From the point of view of regional reality, public cultural service center should be the leading institution to undertake the functions of public cultural service. Specific activities are carried out by various cultural institutions in the region, such as museums, libraries, cultural centers and art galleries [2]. All pavilions and institutions integrate their own resources, give full play to their advantages, and carry out in-depth mass cultural activities in their respective fields to create a prosperous mass cultural atmosphere. At the same time, the rich educational resources in the region, especially various colleges and universities, and numerous cultural celebrities and teachers, are also part of the cultural resources. When organizations carry out activities, they can expand cooperation resources to achieve better results (figure 2).

\subsection{Build a New Media System Supported By Virtual Simulation Technology}

The advent of the information age has brought more convenience to people's life. In People's Daily life, various new media platforms using computer technology have begun to become one of the important tools for people to communicate with the outside world and obtain relevant information. The communication means of new media caters to people's demand for fragmented leisure and entertainment time and meets people's demand for interactive expression, entertainment and information anytime and anywhere, which is the advantage of new media and the focus of traditional culture communication.

How to use new media to improve the communication rate of social science and cultural knowledge, we should use all kinds of cultural institutions to build a good platform of new media, construct a scientific and reasonable platform system of new media, and then edit and plan the content of cultural communication and promotion. News client, WeChat public number, Weibo, trill, posted by more audiences, give priority to with what kind of media which is complementary, how to set up a hierarchy framework of new media, to clear our audience first, locate the user groups, research their main means of acceptance and participation, and the spread of targeted content and operating mechanism. The hierarchical system of new media should be constructed, and the advantages of new media channels should be brought into full play from various angles in order to improve the effect of traditional cultural communication, the acceptance of social science knowledge and the participation in cultural interaction.

\subsection{Long-Term Layout, Effective Operation and Promotion.}

The operation and promotion of new media supported by virtual simulation technology need to be carried out by planning high-quality and highly disseminated content and online activities related to cultural knowledge. Promote the excellent Traditional Chinese cultural knowledge and cultural activities to the audience widely or precisely, increase participation and popularity, so as to make full use of the fan economy and achieve the purpose of raising the social science and cultural literacy of the masses. Broaden your vision, absorb resources, combine the operation of institutions with the operation of business circles, communities and even schools, make reasonable use of resources, and improve the strength and effect of new media content operation. Promotion strategies and methods should be emphasized. New media can not only be a platform for information output, but also pay more attention to giving people the right 
to speak. New media user retention and incentive mechanisms should be established, such as privileges and benefits, points, etc., to shorten the distance between official culture and mass culture and achieve benign interaction.

\section{Strategies of Virtual Simulation Technology Application}

\subsection{Virtual Simulation Technology into the New Media System}

New media as the dissemination of cultural knowledge to promote democratic cultural literacy leading institutions. Sorting out new media platforms and activities related to social science and culture of cultural institutions in the region, integrating superior resources, and building knowledge and activity resource libraries; According to the characteristics of the audience's acceptance and participation, the hierarchical system of new media should be constructed, and the advantages of new media channels should be given full play to in order to improve the masses' acceptance of traditional cultural knowledge and their participation in cultural interaction. Conduct promotion and feedback research, try to use business circle operation and community operation and other ways to put social science lectures and cultural activities of new media into practice and promote them; Analyze the feedback results, establish a quantitative analysis model, test the differences in audience cultural literacy, test the effect of new media means. Conclusions are drawn and rectification suggestions are put forward for future new media culture promotion activities.

Virtual simulation technology embed cultural knowledge and cultural activities into the new media system, and try to reconstruct a series of situations and integrate traditional culture into them by means of similar games. Combine the traditional cultural knowledge and skills needed to improve the audience's cultural literacy, take information transmission and leisure entertainment as the main meeting point, integrate cultural and educational content, adopt the form of independent browsing, humancomputer interaction, gamification task, task-based pass, integrate knowledge modules, knowledge points and steps. Let the public experience highly simulated cultural practice activities that cannot be experienced in daily life at one time (figure 3 ).

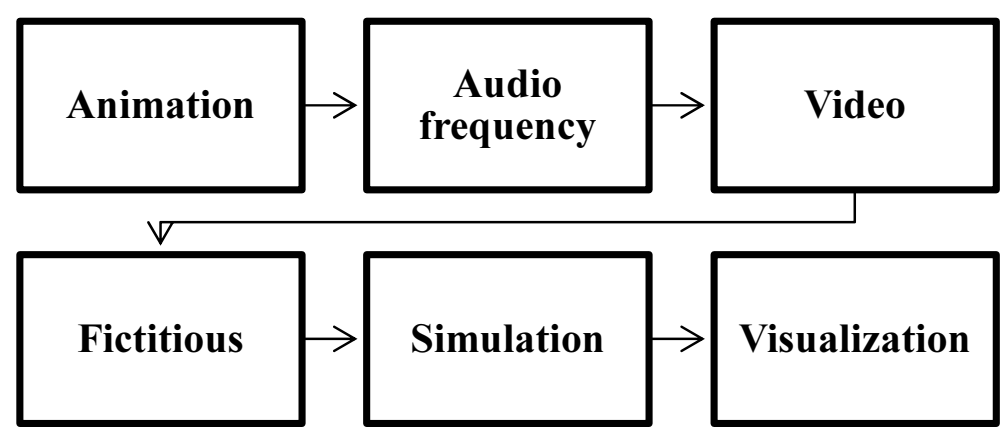

Figure 3. Computer tech shows the connotation of traditional culture 
At the same time, the feedback results can be analyzed according to the computer virtual simulation technology, and a quantitative analysis model can be established to test the audience's acceptance of traditional cultural knowledge, as well as the differences in people's cultural literacy, and test the effect of new media means. Conclusions are drawn and rectification suggestions are put forward for future new media culture promotion activities.

\subsection{Open Online and Offline Channels}

Computer virtual simulation technology is helpful to improve the public's acceptance of new media promotion of social science and cultural knowledge and enhance the public's participation in cultural activities. The emergence of new media has changed the original way of mass communication as large-scale, one-way, central-edge transmission or distribution, and electronic media has gone beyond the definition and definition of the context supported by the material environment. The introduction and widespread use of a new media can change people's lives and minds and produce a range of new social behaviours. In the port of new media, we try to unlock cultural experience levels with different depths in turn through the practice training. Immersive scene experience, full process participation; The model of autonomous and inquirybased learning is adopted to combine cultural communication with literacy improvement while carrying out human-computer interaction. This helps to broaden the means of new media, establish a hierarchical system of new media, combine publicity and promotion with feedback monitoring, and effectively improve the cultural literacy of the audience, or even monitor the cultural literacy level of the audience.

Online experience and offline activities are combined to improve audience literacy through multiple channels. Online computer virtual simulation technology is used to design practical and operable projects, and the most valuable new media platforms such as Weibo and wechat public account are utilized instead of staying at the level of theoretical research. According to the characteristics of audience acceptance and participation, promotion and feedback research are carried out, and the traditional cultural knowledge lectures and cultural activities of new media are put into practice and promoted by means of business circle operation and community operation. Traditional culture resources and the organic integration of new media, make full use of the advantages of computer virtual simulation technology, transmission right values and the depth of thought, train home and the feelings of the masses, social consciousness and citizen consciousness, to the masses to provide enough culture supplies, promote the culture of enthusiasm of the masses, strengthen the cultural confidence, guide the correct world outlook, the outlook on life and values.

\section{Conclusion}

To sum up, the integration of computer virtual simulation technology into the new media system and the organic combination of excellent traditional culture provides an organic carrier and platform for the improvement of people's cultural literacy. $\mathrm{n}$ the context of global integration and diversified development, a thematic mode of traditional cultural communication is set up, which not only focuses on the cultural collision between China's history and reality, but also focuses on various issues in China's social environment, encouraging people to think about and understand China in 
the context of globalization. Due to the convergence of media, the information transmission of new media has the characteristics of high speed, high quality, excessive quantity, diversification and wide range. The identity of information disseminator and audience is no longer obviously different, everyone may be both the information maker and information disseminator, and at the same time act as the identity of information receiver. This paper studies the basis and strategy of integrating computer virtual simulation technology into new media cultural communication system by analyzing the means of traditional culture communication and people's cultural literacy improvement. This paper analyzes the integration of computer virtual simulation technology and new media, and the steps and strategies to promote the dissemination of traditional culture and the improvement of people's cultural literacy by computer virtual simulation technology.

\section{Acknowledgments}

Dalian Federation of Social Science, Liaoning province project: "On the development of new media means to enhance social science and cultural literacy of the masses". Project Number: 2021DLSKZD154; "Light of Textile" Higher Education Teaching Reform research project of China National Textile And Apparel Industry Association (2021) : The integration of Chinese excellent traditional Culture and college writing courses.

\section{References}

[1] Research on new media audio-visual operation technology. Deng Tao, Yin Jun, Zhang Ning, Zhuo Guangwei. Henan Journal of Science and Technology.2017.12.P13-15

[2] Analysis of junior Middle School Information Technology Textbook from the Perspective of Computational Thinking. Shao Zhuxue. Journal of Computers and Telecommunications.2019.12.P 6264,67 